Check for updates

Cite this: RSC Adv., 2019, 9, 8546

Received 22nd November 2018 Accepted 12th February 2019

DOI: $10.1039 / c 8 r a 09630 a$

rsc.li/rsc-advances

\section{Performance of butanol separation from $A B E$ mixtures by pervaporation using silicone-coated ionic liquid gel membranes}

\author{
R. Cabezas, (D) ${ }^{a}$ K. Suazo, ${ }^{a}$ G. Merlet, ${ }^{a}$ E. Quijada-Maldonado, ${ }^{a}$ A. Torres ${ }^{b}$ \\ and J. Romero*a
}

\begin{abstract}
This work aims at the separation of $n$-butanol from aqueous solutions by means of pervaporation using membranes based on gelled ionic liquids (IL). These membranes were mechanically stabilized with a double silicone coating using two polydimethylsiloxane (PDMS) films. The first step of the membrane preparation considered the formation of a gelled ionic liquid layer, which was formed using two different imidazolium-based ionic liquids: [omim] $\left[\mathrm{Tf}_{2} \mathrm{~N}\right]$ and $[\mathrm{bmim}]\left[\mathrm{Tf}_{2} \mathrm{~N}\right]$, and two different phosphonium-based ionic liquids: $\left[\mathrm{P}_{6,6,6,14}\right]\left[\mathrm{Tf}_{2} \mathrm{~N}\right]$ and $\left[\mathrm{P}_{6,6,6,14}\right][\mathrm{DCA}]$. The gelation procedure was carried out on a porous paper support using a low molecular weight gelator. The membranes obtained from this method were tested in pervaporation assays to separate butanol from model ABE (Acetone-Butanol-Ethanol) fermentation solutions. These assays were done in an experimental setup especially built for this purpose. The pervaporation performance of these ionic liquid-based membranes was compared to that obtained with a single PDMS layer membrane. From these experimental results, butanol/water selectivity for $\left[\mathrm{P}_{6,6,6,14}\right]\left[\mathrm{Tf}_{2} \mathrm{~N}\right]$-based membranes reached a value equal to 892 , which is 150 times higher than the value obtained for a single PDMS layer membrane. Simultaneously, for the same IL, the transmembrane fluxes $\left(\mathrm{kg} \mathrm{h}^{-1} \mathrm{~m}^{-2}\right.$ ) of butanol and water were $37 \%$ and $99.6 \%$ lower than the values obtained using a single PDMS layer membrane, respectively. The hydrophobic character of the selected ionic liquid and its relatively high values for the transport parameters can explain this experimental response.
\end{abstract}

\section{Introduction}

Biobutanol is a promising second-generation biofuel because of its particular properties similar to gasoline and better compatibility with current gasoline infrastructure, ${ }^{1}$ showing several advantages over other bio-alcohols such as: low volatility, high calorific value, easy mixing with gasoline and no ignition problems in conventional engines. ${ }^{2,3}$ During the early part of the twentieth century, the ABE fermentation process was widely used in the production of acetone. However, butanol has predominantly been produced by petrochemical processes mainly due to the bioproduction cost. ${ }^{4,5} \mathrm{ABE}$ fermentation is a butanol production process that employs a strain of bacteria from the Clostridium family to fermentate a starch substrate, sugar beets, glucoses, cellulosic-based materials and other biomass feedstocks. Even though enormous efforts have been made in strain and process engineering, butanol concentration in fermentation broth is difficult to exceed $2 \%(\mathrm{w} / \mathrm{v})$ in

${ }^{a}$ Laboratory of Membrane Separation Processes (LabProSeM), Department of Chemical Engineering, U. de Santiago de Chile, Av. Lib. Bdo. O'Higgins 3363, Estación Central, Santiago, Chile. E-mail: julio.romero@usach.cl; Tel: +562 7181821

${ }^{b}$ Laboratory of Food Packaging, Department of Food Science and Technology, U. de Santiago de Chile, Santiago, Chile conventional batch fermentation. This process has again gained attention due to the depletion of fossil fuels. Nevertheless, there are several current challenges in the production of butanol from biologic routes.

The product recovery from the fermentation broth represents a key aspect in the global production process. Furthermore, in situ product recovery techniques effectively reduce the production cost by continuous removal and purification of inhibitory products during fermentation, which will also promote the development of biobutanol production. ${ }^{1}$ In this way, the recovery of butanol by pervaporation has been widely investigated using different types of membranes, since this product is particularly diluted in the fermentation broth. Thus, the implementation of an effective separation process with low energy requirements represents relevant progress in the use of butanol as a biofuel. This goal could be achieved if the proposed separation process cleverly combines advantageous transport properties and thermodynamic equilibrium conditions. One of the processes that could combine these parameters in the right direction is pervaporation. This membrane technique combines the phenomena of permeation and evaporation, putting a membrane between a liquid and gas phases in order to achieve separation through the phase change but including the selectivity of a dense membrane. 
A feed liquid mixture contacts one side of a membrane; permeate is removed as a vapor from the other side. Transport through the membrane is induced by the vapor pressure difference between the feed solution and the permeate vapor. This vapor pressure difference can be maintained in several ways. At the laboratory scale, a vacuum pump is usually used to draw a vacuum on the permeate side of the system. At the industrial scale, the permeate vacuum could be most economically generated by cooling the permeate vapor, causing condensation, which spontaneously creates a partial vacuum. ${ }^{6}$

Primary products of ABE fermentation are acetone, butanol, and ethanol often in a $3: 6: 1$ mass ratio. The recovery of butanol by pervaporation has been widely studied, ${ }^{7,8}$ and various membranes have been used for butanol separation from fermentation broths, those membranes were made from different materials such as polydimethylsiloxane (PDMS), zeolite or silicalite-filled siloxane, ${ }^{7,8}$ poly(ether-block-amide),${ }^{9}$ poly(vinylidene fluoride), ${ }^{10}$ ceramic composites of PDMS ${ }^{11}$ and low-density polyethylene, LDPE. ${ }^{12}$

\section{Ionic liquid-based membranes for butanol separation}

Ionic liquids (ILs) show several advantages over conventional solvents such as a negligible vapor pressure and the capacity to solvate a variety of organic and inorganic species. ILs have been described as organic salts with a relatively large organic cation and an organic or inorganic anion, and melting points lower than $373 \mathrm{~K}^{13}$ These compounds have a unique array of physicochemical properties, which make them suitable in several applications where the conventional organic solvents are not sufficiently effective or not applicable.

Many of the ILs are both air and moisture stable; however, this depends on their hydrophilic/hydrophobic character. The degree of the hydroscopic character of the IL and, consequently, the interaction between water and IL strongly depends on anions of the IL. The use of ILs in membrane techniques has been investigated with promising results. ${ }^{12-18}$ In this way, supported ionic liquid membranes (SILMs) represent the first step in the development of membrane separation processes based on the properties of ionic liquids where a macroporous membrane contains an ionic liquid into its pores. ${ }^{15-19}$ However, the application of these membranes for pervaporation of butanol has been recently studied by de los Ríos and coworkers ${ }^{20}$ who have studied the extraction of butanol from transesterification reaction through SILMs containing tetrafluoroborate based ionic liquids, but the main problem of SILMs application was their low stability caused by carrier solvent losses during operation. Cascon and Choudhari ${ }^{21}$ investigated the intrinsic stabilities of simple supported hydrophobic ammonium and phosphonium ionic liquid membranes and their pervaporative recoveries of 1-butanol from dilute aqueous solutions, with the same problem. Meanwhile, in a previous work, Plaza and coworkers ${ }^{15}$ generated an improved stability of the supported ionic liquid membranes, gelling the ionic liquid within the pores according to the procedure reported by Voss and coworkers, ${ }^{22}$ for pervaporation of butanol from an ABE fermentation, reporting a best performance of the membrane, but the pervaporation cannot be made with a vacuum, for the drag of the ionic liquid from the porous support. A step forward in terms of mechanical stability was accomplished by the polymerization of the ionic liquid in the membrane matrix, but this was associated to a significant decrease of the transport properties when the selective phase becomes a polymer. ${ }^{23}$

On the other hand, Heitmann and collaborators immobilized tetracyanoborate and tris(pentafluoro-ethyl) trifluorophosphate by dissolution in poly(ether block amide); but the best result was obtained when there was a change of the structure of the membrane from a support membrane to an asymmetric membrane. ${ }^{24}$ An ultrafiltration membrane, impregnated with 1-ethenyl-3-ethyl-imidazolium hexafluorophosphate and tetrapropylammonium tetracyano-borate and polydimethylsiloxane, was one of the first asymmetric membranes for butanol recovery by vacuum pervaporation..$^{25}$ Some drawbacks in this configuration involved the influence of ionic liquids in the polymer ${ }^{23}$ and the poor stability of the SILM. ${ }^{26}$ Other authors propose the preparation of pervaporation membranes based on ionic liquids coated by polymer layers. This configuration seems to be a stable option combining the excellent transport properties of ionic liquids with the stability and strength of the polymers. ${ }^{27,28}$ Furthermore, the ionic liquid layer is not in direct contact with the solutions to be treated.

The present contribution describes the separation performance of a pervaporation membrane prepared from two different imidazolium ionic liquids ([omim] $\left[\mathrm{Tf}_{2} \mathrm{~N}\right]$ and [bmim] $\left.\left[\mathrm{Tf}_{2} \mathrm{~N}\right]\right)$, and two different phosponium ionic liquids $\left(\left[\mathrm{P}_{6,6,6,6,14}\right]\right.$ $\left[\mathrm{Tf}_{2} \mathrm{~N}\right]$ and $\left.\left[\mathrm{P}_{6,6,6,14}\right][\mathrm{DCA}]\right)$, which are well known by their selectivity to separate butanol from aqueous mixtures. Thus, silicone-coated ionic liquid membranes have been developed in this work for the selective removal of butanol from $\mathrm{ABE}$ (acetone/butanol/ethanol) mixture membranes. The mechanical stability of the ionic liquid into the membrane structure is achieved by means of its gelation using a low molecular weight gelator. $^{22}$

\section{Experimental procedure}

\subsection{Materials and reagents}

Ionic liquids 1-butyl-3-methylimidazolium bis(trifluoromethanesulfonyl)imide, 1-octyl-3-methylimidazolium bis(trifluoromethanesulfonyl)imide, trihexyl(tetradecyl)phosphonium dicyanamide and trihexyl(tetradecyl)phosphonium bis(trifluoromethanesulfonyl)imide, [bmim] $\left[\mathrm{Tf}_{2} \mathrm{~N}\right], \quad[\mathrm{omim}]$ $\left[\mathrm{Tf}_{2} \mathrm{~N}\right],\left[\mathrm{P}_{6,6,6,14}\right][\mathrm{DCA}]$ and $\left[\mathrm{P}_{6,6,6,14}\right]\left[\mathrm{Tf}_{2} \mathrm{~N}\right]$ with synthesis grade, were supplied by Iolitec. 12-Hydroxystearic acid $(99 \% \mathrm{w} / \mathrm{w})$, acetone, butan-1-ol and ethanol with analytical grade were purchased from Sigma Aldrich.

On the other hand, PDMS membranes were purchased from Kolm ${ }^{\circledR}$, Chile. These membranes were selected from their organophilic character and as one of the most used materials in pervaporation membranes. The model ABE solutions were prepared by mixing acetone, butanol and ethanol with 
deionized water (>18 M $\Omega$ ) obtained from a Purelab Classic Co. Water System.

The structures of the ILs tested in this study are summarized in Table 1.

\subsection{Membrane preparation}

The ionic liquid-based membranes were prepared in two steps, the first one involved the formation of an IL gel layer on a support of porous paper, which was placed on a PDMS layer. The IL gel layer and the PDMS layer have a thickness of $150 \mu \mathrm{m}$ each. The IL gel was prepared by mixing the ionic liquid, with 12-hydroxystearic acid as a low molecular weight gelator. Previous tests showed that 12-hydroxystearic was an effective gelator when it is dissolved in the ILs at concentrations equal to $0.6 \% \mathrm{w} / \mathrm{w}^{15,22}$ The mixture containing the IL and 12-hydroxystearic acid was heated at $80{ }^{\circ} \mathrm{C}$ and kept in an ultrasonic bath in order to ensure complete solubilization. The solution was spilled on the porous support placed on a PDMS film.

In a second step, a second PDMS layer with the same characteristics of the first one was placed on the IL gel layer to finish the PDMS coating. The membrane obtained from this procedure is placed under vacuum in a chamber where the temperature decreased from $80{ }^{\circ} \mathrm{C}$ to $20{ }^{\circ} \mathrm{C}$ at a decreasing rate of $1{ }^{\circ} \mathrm{C} \min ^{-1}$.

Fig. 1 schematically describes the obtained membrane (surface area: $2 \times 10^{-2} \mathrm{~m}^{2}$ ). Fig. $1 \mathrm{~b}$ shows a cross section of the pervaporation membrane used in this work.

\subsection{Pervaporation experiments}

The flat sheet membranes prepared according to the procedure described in Section 3.2 were tested in pervaporation runs,

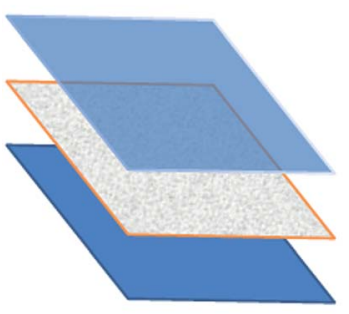

(A)

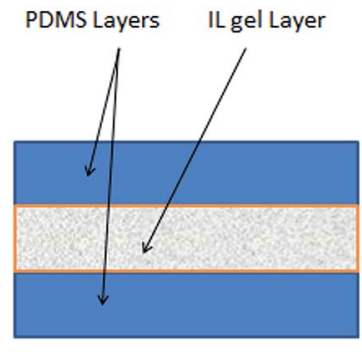

(B)
Fig. 1 (A) Schematic description of the silicone-coated IL gel membrane preparation and its structure; (B) cross section view of the three-layer membrane.

which were carried out in a lab scale pervaporation setup, especially designed for this purpose. This experimental setup, described in the outline of Fig. 2, considers an ABE aqueous solution stream, which is circulated by means of a peristaltic pump that recirculates this solution in a vessel placed in a thermoregulated water bath. A module specially designed to contain the IL-based membrane separates the solution stream and a vacuum line on the permeate side. A vacuum was generated with a PC 3001 Vario® vacuum pump. All experiments were done at a vacuum pressure of $30 \mathrm{mbar}$ on the permeate side and with a constant temperature of the $\mathrm{ABE}$ solution equal to $30{ }^{\circ} \mathrm{C}$. Permeate was collected in a cold trap, which contained liquid nitrogen.

Membranes were stored in a flask containing an ABE solution with the same initial solute concentrations that the feed one used in the pervaporation tests.

Table 1 Ionic liquids used in this work

\begin{tabular}{|c|c|c|}
\hline Name & Structure & Abbreviation \\
\hline 1-Butyl-3-methylimidazolium bis(trifluoromethanesulfonyl)imide & & {$[\mathrm{bmim}]\left[\mathrm{Tf}_{2} \mathrm{~N}\right]$} \\
\hline 1-Octyl-3-methylimidazolium bis(trifluoromethanesulfonyl)imide & & {$[\mathrm{omim}]\left[\mathrm{Tf}_{2} \mathrm{~N}\right]$} \\
\hline Trihexyl(tetradecyl)phosphonium dicyanamide & & {$\left[\mathrm{P}_{6,6,6,14}\right][\mathrm{DCA}]$} \\
\hline Trihexyl(tetradecyl)phosphonium bis(trifluoromethanesulfonyl)imide & & {$\left[\mathrm{P}_{6,6,6,14}\right]\left[\mathrm{Tf}_{2} \mathrm{~N}\right]$} \\
\hline
\end{tabular}




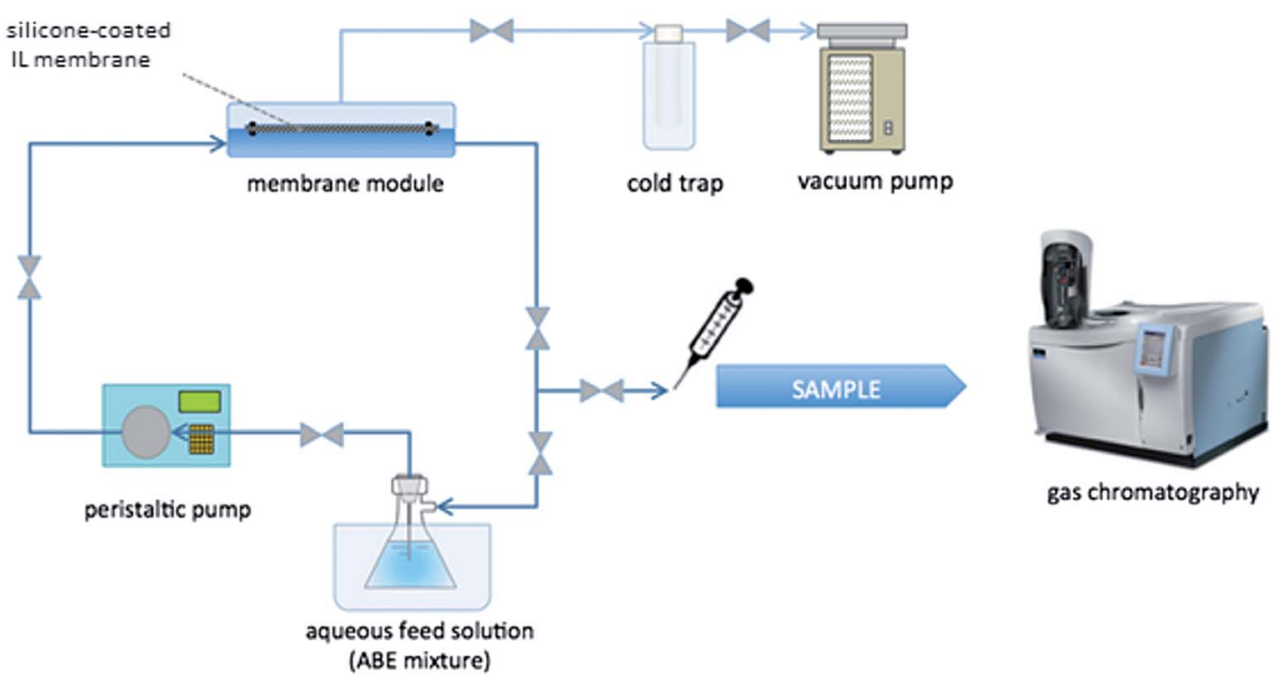

Fig. 2 Outline of the lab-scale experimental setup for pervaporation tests.

Table 2 Operating conditions of pervaporation tests

\begin{tabular}{lll}
\hline Variable & Value (s) & Units \\
\hline ABE solution flow rate & $0.48,0.90,1.25$ & $\mathrm{~L} \mathrm{~min}^{-1}$ \\
Concentration of solutes & Butanol: 12 & $\mathrm{~kg} \mathrm{~m}^{-3}$ \\
& Ethanol: 2 & \\
& Acetone: 6 & \\
Volume of feed solution & 0.125 & $\mathrm{~L}$ \\
Absolute pressure of permeate & 30 & $\mathrm{mbar}$ \\
Temperature & 30 & ${ }^{\circ} \mathrm{C}$
\end{tabular}

The concentration changes of butanol, acetone and ethanol were monitored as a function of time collecting five samples from the feed solution vessel. These samples $(1 \mu \mathrm{L})$ were analyzed by gas chromatography in a Perkin Elmer Clarus 500 GC with a Carbowax column using a FID. Samples were collected from the vessel containing the ABE feed solution and from the cold trap containing the condensate of the mixture that permeates through the membrane. The samples obtained from both sources were analyzed to verify the mass balance for each compound.

Operating parameters of pervaporation runs are summarized in Table 2 .

From this experimental procedure, which follows the concentration decrease of each compound as a function of time, the extraction percentage and the transmembrane flux $\left(\mathrm{kg} \mathrm{m}^{-2}\right.$ $\mathrm{h}^{-1}$ ) of each specie could be estimated by eqn (1) and (2), respectively:

$$
\begin{gathered}
\text { Extraction } \%=\frac{\left(C_{\mathrm{i}-\mathrm{f}}^{\text {initial }}-C_{\mathrm{i}-\mathrm{f}}{ }^{t+\Delta t}\right)}{C_{\mathrm{i}-\mathrm{f}}^{\text {initial }}} \\
N_{\mathrm{i}}{ }^{t}=\frac{\left(V^{t} C_{\mathrm{i}-\mathrm{f}}{ }^{t}-V^{t+\Delta t} C_{\mathrm{i}-\mathrm{f}}{ }^{t+\Delta t}\right)}{A \Delta t}
\end{gathered}
$$

where $N_{\mathrm{i}}{ }^{t}$ is the instantaneous transmembrane flux of the specie $\mathrm{i}$, and $C_{\mathrm{i}-\mathrm{f}}{ }^{t}$ and $C_{\mathrm{i}-\mathrm{f}}{ }^{t+\Delta t}$ represent the concentration of the same compound in the feed solution at the time $t$ and in the next time step $t+\Delta t$, respectively. Moreover, $A$ is the membrane surface area available for mass transfer.

On the other hand, the experimental transmembrane flux of water was assessed by calculating the mass balance of water, which was based on the measurement of ABE-mixed concentrations on the permeate side collected in a cold trap and the total decrease of the concentrations of the ABE fermentation products on the feed solution side.

From the pervaporation tests, two other experimental responses were estimated: the selectivity of species with respect to water, and the enrichment ratio of each compound. Thus, the selectivity of the solute $i$ with respect to water can be estimated by eqn (3):

$$
\alpha_{\mathrm{i} / \mathrm{w}}=\left\{\frac{\left(\frac{C_{\mathrm{i}-\mathrm{p}}}{C_{\mathrm{w}-\mathrm{p}}}\right)}{\left(\frac{C_{\mathrm{i}-\mathrm{f}}}{C_{\mathrm{w}-\mathrm{f}}}\right)}\right\}
$$

where $C_{\mathrm{i}-\mathrm{p}}$ and $C_{\mathrm{i}-\mathrm{f}}$ are the concentrations of the compound $\mathrm{i}$ in the whole mass of the collected permeate and in the feed solution after the pervaporation process, respectively. Meanwhile, $C_{\mathrm{w}-\mathrm{p}}$ and $C_{\mathrm{w}-\mathrm{f}}$ represent the concentrations of water in the whole mass of collected permeate and in the feed solution after the pervaporation process, respectively. Furthermore, the enrichment ratio of each compound can be estimated as the concentration ratio between its value in the whole mass of the collected permeate and its value in the feed solution after pervaporation. Thus, this experimental response could be calculated from the following equation:

$$
\beta_{\mathrm{i}}=\left\{\frac{C_{\mathrm{i}-\mathrm{p}}}{C_{\mathrm{i}-\mathrm{f}}}\right\}
$$

This ratio has been calculated for all the species present in the ABE solution including water. The experimental responses described by means of eqn (1)-(4) have been calculated for 

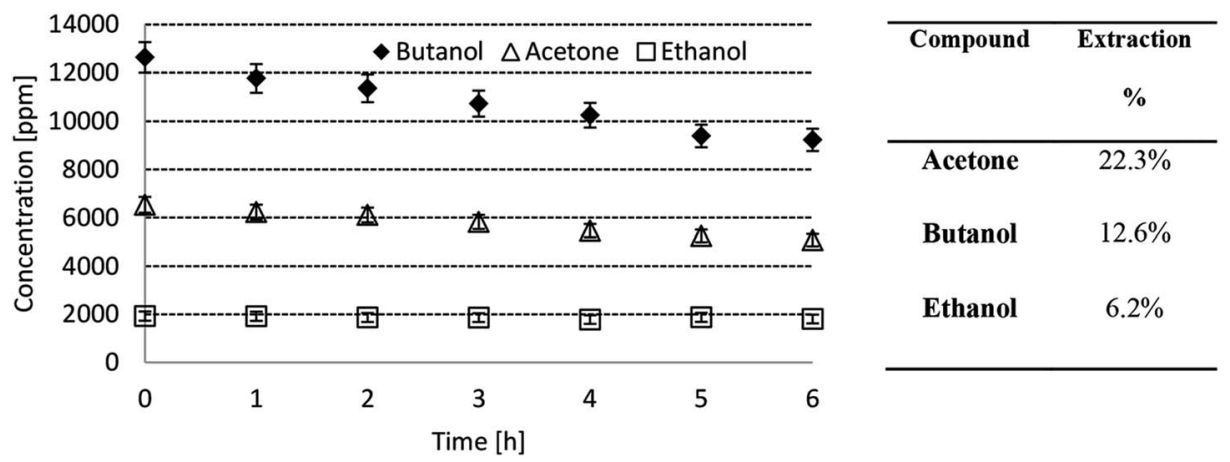

Fig. 3 Concentration of butanol, acetone and ethanol in the feed solution as a function of time during the pervaporation test using a PDMScoated [omim] $\left[\mathrm{Tf}_{2} \mathrm{~N}\right]$ gel membrane. ABE solution flow rate was $0.9 \mathrm{~L} \mathrm{~min}{ }^{-1}$; temperature and absolute permeate pressure were $30{ }^{\circ} \mathrm{C}$ and 30 mbar, respectively.

pervaporation tests using a single PDMS layer as reference membrane system and the four different PDMS-coated ionic liquid gel membranes prepared in this work. All pervaporation experiments were carried out in duplicate with the goal to obtain the variability of the process.

\section{Results and discussion}

\subsection{Mass transfer rate through the PDMS-coated IL gel membranes}

The pervaporation tests described in Section 3.3 were carried out for the membranes prepared with the four ILs selected in this study and mentioned above. Thus, Fig. 3 shows an example of the results obtained in these experiments with the PDMScoated IL gel membrane where the concentration of each compound in the feed ABE solution decreases as a function of time. From this figure, it can be seen that the clearest decrease is in the concentration of butanol and acetone. Meanwhile, the concentration of ethanol could be considered practically constant during the time of the pervaporation test. The mass transfer of every compound through the membrane depends on a combination of transport and equilibrium steps, which take into account the interfacial properties and the properties of each membrane layer itself. Thus, the lower transfer rate of ethanol, which is the smallest molecule among these solutes, could be explained by a smaller solubility of this alcohol in the PDMS layers that coat the IL membrane layer. The values of the solubility parameter of the Flory-Huggins equation are reported

Table 3 Interaction parameter between permeate components and PDMS membrane ${ }^{10}$

\begin{tabular}{lll}
\hline Component & Solubility parameter $\mathrm{MPa}^{1 / 2}$ & $\begin{array}{l}\text { Interaction } \\
\text { parameter }\end{array}$ \\
\hline PDMS & 14.9 & - \\
Acetone & 19.7 & 1.5 \\
Butanol & 23.3 & 7.2 \\
Ethanol & 26.2 & 8.8 \\
Water & 47.9 & 30.3
\end{tabular}

in Table 3 for each compound in the feed solution and for PDMS. From these solubility parameters, it is possible to calculate the interaction parameter; a higher value of the interaction parameter involves a lower affinity between the compound and PDMS. Thus, the lowest affinities with PDMS are estimated for both water and ethanol. These compounds show the lowest transfer rates through the membrane.

From the decrease of concentration as a function of time obtained through the results reported in Fig. 3, it is possible to estimate the instantaneous transmembrane flux for each specie by means of eqn (2). These results are presented in Fig. 4 when the PDMS-coated [omim] $\left[\mathrm{Tf}_{2} \mathrm{~N}\right]$ gel membrane was used. These fluxes were also estimated for the other three IL gel membranes as well as for the reference system constituted by a single PDMS layer. This choice is justified in order to avoid issues that could involve the underestimation of the transfer rate in this system because two PDMS layers with mechanical contact can store a gas gap between them. Thus, a single layer was used in order to avoid the separation of the layers in the solid-solid interface during the pervaporation process. In this case, the permeation through a double-layer system should show half of the permeation value reported in this work. Fig. $4 \mathrm{a}-\mathrm{c}$ show the transmembrane fluxes of acetone, butanol and ethanol for the same membrane based on [omim] $\left[\mathrm{Tf}_{2} \mathrm{~N}\right]$ considering three different feed solution flow rates, which vary from 0.48 to $1.25 \mathrm{~L} \mathrm{~min}^{-1}$. There is no significant influence of the feed flow rate on the transmembrane flux of each specie. This result is expected, since the thickness of the three-layer membrane is significant compared to the mass transfer resistance related to the feed solution boundary layer at the proximities of the membrane.

The preferential transfer through the membrane is observed for butanol, a result that could be considered expected because this solute is the most concentrated one in the mixture. Thus, the highest flux was observed for the compound that shows the highest concentration gradient through the membrane. Meanwhile, acetone with half of this concentration could be considered as an easily transferred compound.

On the other hand, ethanol is poorly transferred through the membrane, which was previously explained by the interaction with the PDMS layers. 

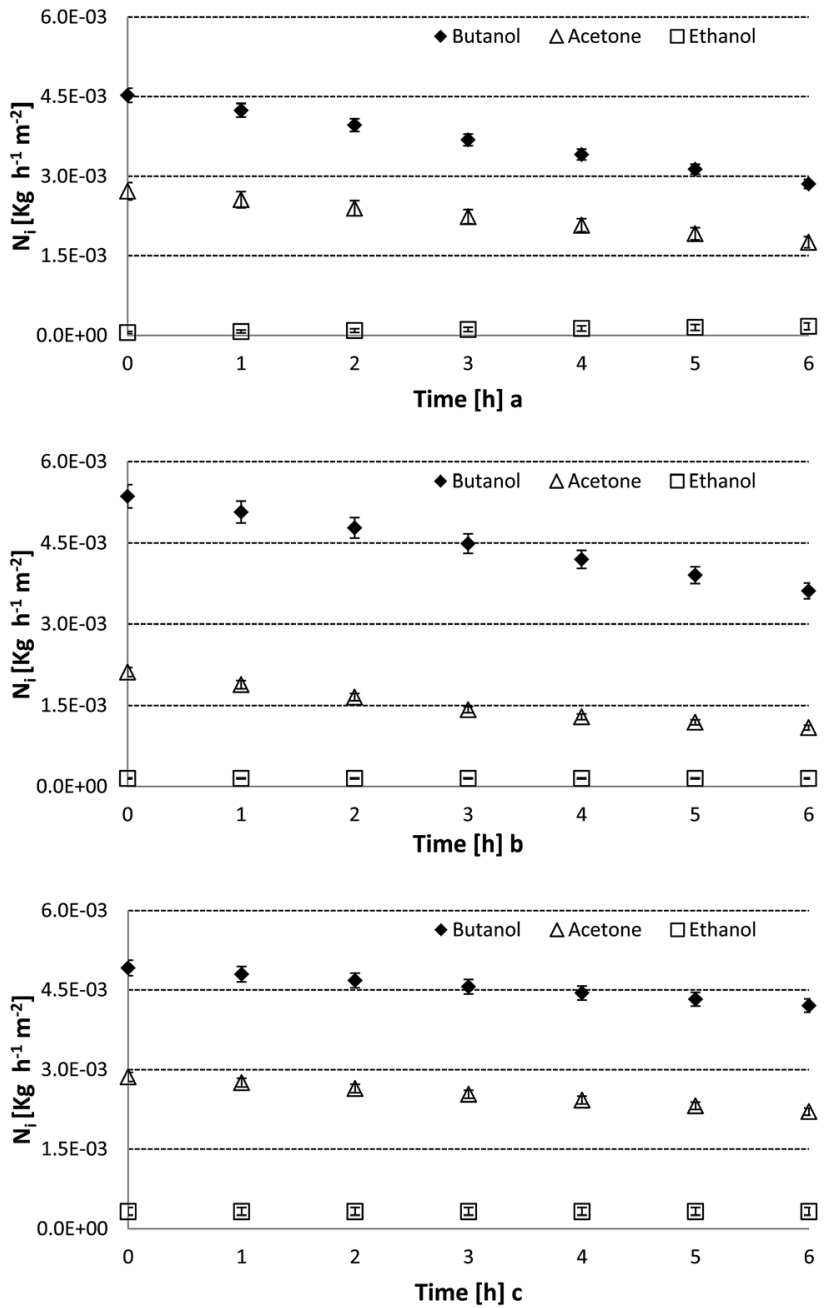

Fig. 4 Transmembrane flux of butanol, acetone and ethanol as a function of time for PDMS-coated [omim] $\left[\mathrm{Tf}_{2} \mathrm{~N}\right]$ gel membrane at different $A B E$ solution flow rates. (a), (b) and (c) show results at feed solutions flow rates equal to $0.48,0.90$ and $1.25 \mathrm{~L} \mathrm{~min}^{-1}$, respectively.

On the other hand, Fig. 5 shows the results obtained with the single PDMS layer membrane as well as the four PDMS-coated IL gel membranes prepared in this work.

Firstly, Fig. 5 shows that the inclusion of the IL gel layer coated by the PDMS layers enhances a preferential transfer of butanol over the other two solutes present in the ABE mixtures, the membrane prepared with $[\mathrm{omim}]\left[\mathrm{Tf}_{2} \mathrm{~N}\right]$ shows the highest difference between the transmembrane flux of butanol and the fluxes of the other products. The results of transmembrane fluxes of acetone, butanol and ethanol observed in Fig. 5a are the highest values of this set of experiments because this represents the thinner membrane with the lowest mass transfer resistance. Nevertheless, the transmembrane fluxes of butanol and acetone are not significantly lower in the PDMS-coated IL gel membranes, despite the thicknesses of these membranes, which are close to three times higher than the value in the single PDMS layer membrane. This response can be explained by the significant decrease of the global flux of the four compounds of the mixture where the largest decrease can be observed for the transmembrane flux of water. Thus, the
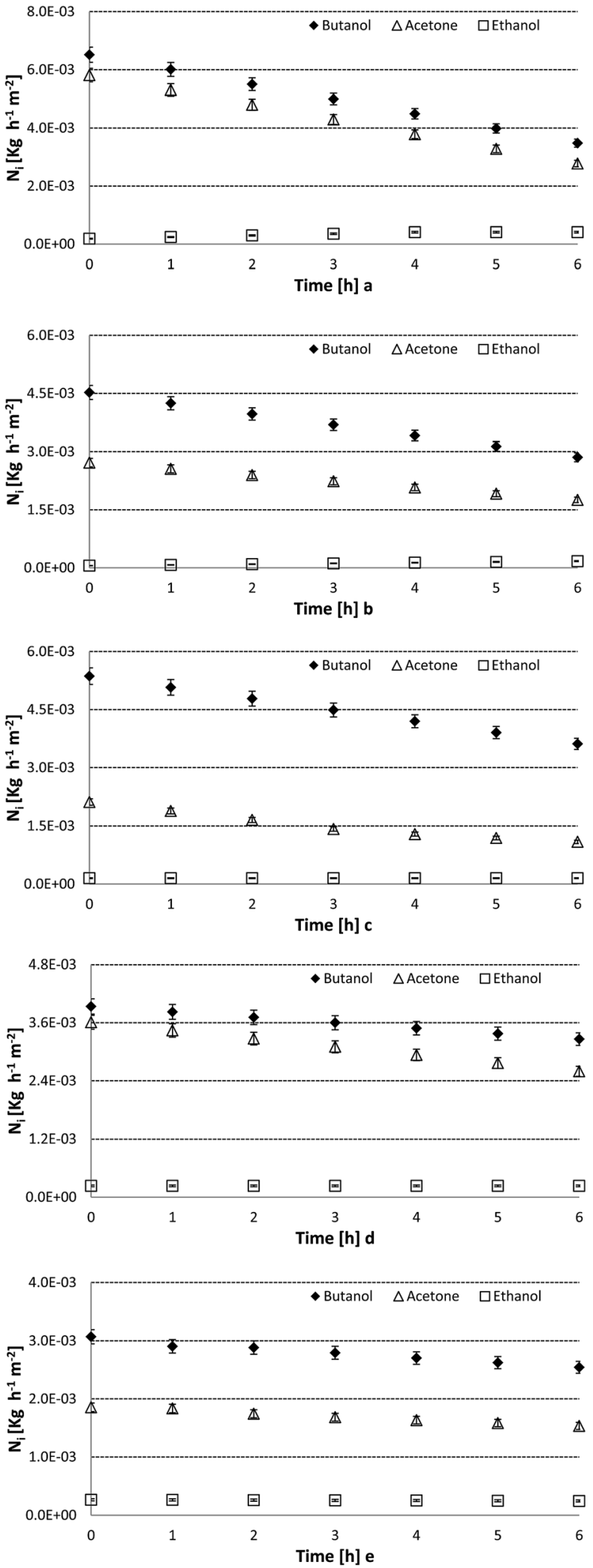

Fig. 5 Transmembrane flux of butanol, acetone and ethanol as a function of time for different membranes at $A B E$ solution flow rate 0.9 $\mathrm{L} \mathrm{min}^{-1}$; temperature and absolute permeate pressure $30{ }^{\circ} \mathrm{C}$ and 30 mbar, respectively. Fluxes for (a) a single PDMS layer membrane; (b) a PDMS-coated [bmim] [Tf ${ }_{2} \mathrm{~N}$ ] gel membrane; (c) a PDMS-coated [omim] $\left[\mathrm{Tf}_{2} \mathrm{~N}\right]$ gel membrane; (d) a PDMS-coated $\left[\mathrm{P}_{6,6,6,14}\right][\mathrm{DCA}]$ membrane, and (e) a PDMS-coated $\left[\mathrm{P}_{6,6,6,14}\right]\left[\mathrm{Tf}_{2} \mathrm{~N}\right]$ gel membrane. 
Table 4 Average transmembrane flux $\left(\mathrm{kg} \mathrm{h}^{-1} \mathrm{~m}^{-2}\right)$ of each compound for the different membranes tested in this work

\begin{tabular}{|c|c|c|c|c|}
\hline \multirow[b]{2}{*}{ Membrane } & \multicolumn{4}{|c|}{ Transmembrane flux $\left(\mathrm{kg} \mathrm{m}^{-2} \mathrm{~h}^{-1}\right)$} \\
\hline & Butanol & Acetone & Ethanol & Water \\
\hline Single PDMS layer & $5.22 \times 10^{-3}$ & $4.48 \times 10^{-3}$ & $3.82 \times 10^{-4}$ & $8.02 \times 10^{-2}$ \\
\hline PDMS-coated [bmim] $\left[\mathrm{Tf}_{2} \mathrm{~N}\right]$ gel & $3.82 \times 10^{-3}$ & $2.39 \times 10^{-3}$ & $1.81 \times 10^{-4}$ & $1.23 \times 10^{-2}$ \\
\hline PDMS-coated [omim] $\left[\mathrm{Tf}_{2} \mathrm{~N}\right]$ gel & $4.44 \times 10^{-3}$ & $1.90 \times 10^{-3}$ & $1.55 \times 10^{-4}$ & $6.01 \times 10^{-3}$ \\
\hline PDMS-coated $\left[\mathrm{P}_{6,6,6,14}\right][\mathrm{DCA}]$ gel & $3.52 \times 10^{-3}$ & $3.02 \times 10^{-3}$ & $9.19 \times 10^{-5}$ & $2.14 \times 10^{-2}$ \\
\hline PDMS-coated $\left[\mathrm{P}_{6,6,6,6,14}\right]\left[\mathrm{Tf}_{2} \mathrm{~N}\right]$ gel & $3.16 \times 10^{-3}$ & $2.09 \times 10^{-3}$ & $2.85 \times 10^{-4}$ & $2.89 \times 10^{-4}$ \\
\hline
\end{tabular}

average fluxes of butanol and acetone through the IL gel membranes decrease less than $60 \%$ compared to the fluxes though the single PDMS membrane. The flux of ethanol decreases up to $75 \%$ in the IL gel membrane when compared with the reference system. However, the transmembrane flux of water through the IL gel membranes shows a decrease up to 99.996\% with respect to the same value in the single PDMS layer. These results are summarized in Table 4 .

In this framework, Fig. $5 \mathrm{~b}-\mathrm{e}$, as well as the Table 4 , show that the IL gel membrane with the highest flux of butanol is the prepared one with [omim] [ $\left.\mathrm{Tf}_{2} \mathrm{~N}\right]$. However, the membranes with the clearest preferential transport of butanol are those prepared with the IL $\left[\mathrm{P}_{6,6,6,14}\right]\left[\mathrm{Tf}_{2} \mathrm{~N}\right]$.

Table 4 shows how the incorporation of an ionic liquid gel film between the PDMS layers modifies the affinity of the membrane for the ABE fermentation products with transmembrane fluxes of butanol 1.16, 1.59, 2.33, 1.17 and 1.51 times higher than those of acetone for PDMS, [bmim] $\left.\mathrm{Tf}_{2} \mathrm{~N}\right]$, [omim] $\left[\mathrm{Tf}_{2} \mathrm{~N}\right],\left[\mathrm{P}_{6,6,6,14}\right][\mathrm{DCA}]$, and $\left[\mathrm{P}_{6,6,6,14}\right]\left[\mathrm{Tf}_{2} \mathrm{~N}\right]$ membranes, respectively. In this way, the affinity of the ionic liquid for butanol seems to be related to the length to the alkyl chain in the cation; meanwhile, the hydrophobic character could be related to the combination of these cations with the anion $\left[\mathrm{Tf}_{2} \mathrm{~N}\right]^{-}$. In this work, imidazolium and phosphonium cations show, as in Table 4 , the lowest values of transmembrane flux of water when there were combined with $\left[\mathrm{Tf}_{2} \mathrm{~N}\right]^{-}$.

From the experimental results reported in Table 4, it is possible to observe that the single PDMS layer membrane shows the highest fluxes of all compounds including water. This is expected because this membrane shows the lowest thickness and mass transfer resistance. However, the inclusion of an ionic liquid layer involves a moderate decrease in the flux of the fermentation products: acetone, butanol, and ethanol. In this way, the PDMScoated membranes prepared in this work show a thickness close to three times higher than the single PDMS layer membrane used as a reference. These results show that the increase of mass transfer resistance, which involves the inclusion of an ionic liquid gel layer, is mainly concentrated in the decrease of the transmembrane flux of water. The membrane prepared with [omim] $\left[\mathrm{Tf}_{2} \mathrm{~N}\right]$ gel presents an average transmembrane flux of butanol only $17 \%$ lower than the single PDMS layer membrane.

\subsection{Selectivity of the fermentation products with respect to water}

Table 5 shows the values of selectivity of each specie with respect to water where the membranes prepared with gelled
Table 5 Selectivity of each specie with respect to water through different membranes tested in this work

\begin{tabular}{|c|c|c|c|}
\hline \multirow[b]{2}{*}{ Membrane } & \multicolumn{3}{|c|}{ Solute/water selectivity } \\
\hline & Butanol & Acetone & Ethanol \\
\hline Single PDMS layer & 6.0 & 10.3 & 2.6 \\
\hline PDMS-coated $[\mathrm{bmim}]\left[\mathrm{Tf}_{2} \mathrm{~N}\right]$ gel & 25.6 & 27.4 & 5.2 \\
\hline PDMS-coated $[$ omim $]\left[\mathrm{Tf}_{2} \mathrm{~N}\right]$ gel & 62.3 & 45.8 & 13.0 \\
\hline PDMS-coated $\left[\mathrm{P}_{6,6,6,14}\right][\mathrm{DCA}]$ gel & 14.2 & 18.4 & 2.2 \\
\hline PDMS-coated $\left[\mathrm{P}_{6,6,6,14}\right]\left[\mathrm{Tf}_{2} \mathrm{~N}\right]$ gel & 892.0 & 1181.2 & 483.0 \\
\hline
\end{tabular}

$\left[\mathrm{P}_{6,6,6,14}\right]\left[\mathrm{Tf}_{2} \mathrm{~N}\right]$ and $[\mathrm{omim}]\left[\mathrm{Tf}_{2} \mathrm{~N}\right]$ were the most selective ones. The key to these high selectivity values is the low permeation of water observed through the membrane prepared with $\left[\mathrm{P}_{6,6,6,14}\right]$ $\left[\mathrm{Tf}_{2} \mathrm{~N}\right]$. Meanwhile, the membrane based on $[\mathrm{omim}]\left[\mathrm{Tf}_{2} \mathrm{~N}\right]$ shows the highest transmembrane flux of butanol and a relatively high rejection to water. In the same way, Table 6 shows the enrichment ratio for each specie using the different membranes tested in this study.

The permeate obtained with the most selective membranes involves concentrations of $38 \%$ butanol, $10 \%$ acetone, $2 \%$

Table 6 Enrichment ratio of each specie through different membranes tested in this work

\begin{tabular}{|c|c|c|c|}
\hline \multirow[b]{2}{*}{ Membrane } & \multicolumn{3}{|c|}{ Enrichment ratio } \\
\hline & Butanol & Acetone & Ethanol \\
\hline Single PDMS layer & 4.8 & 8.3 & 2.1 \\
\hline PDMS-coated $[$ bmim $]\left[\mathrm{Tf}_{2} \mathrm{~N}\right]$ gel & 17.0 & 21.3 & 4.8 \\
\hline PDMS-coated [omim] $\left[\mathrm{Tf}_{2} \mathrm{~N}\right]$ gel & 29.6 & 25.3 & 6.2 \\
\hline PDMS-coated $\left[\mathrm{P}_{6,6,6,14}\right][\mathrm{DCA}]$ gel & 10.5 & 18.0 & 1.6 \\
\hline PDMS-coated $\left[\mathrm{P}_{6,6,6,14}\right]\left[\mathrm{Tf}_{2} \mathrm{~N}\right]$ gel & 45.2 & 59.8 & 24.5 \\
\hline
\end{tabular}

Table 7 Values of viscosity of ILs, diffusion coefficient of butanol $\left(D_{\mathrm{AB}}\right)$ and water concentration at saturation condition for each ionic liquid tested in this work

\begin{tabular}{llll}
\hline $\begin{array}{l}\text { Ionic } \\
\text { liquid }\end{array}$ & $\begin{array}{l}\mu \\
\left.[\mathrm{cp}]_{(25}{ }^{\circ} \mathrm{C}\right)\end{array}$ & $\begin{array}{l}D_{\text {butanol-IL }} \\
\left.\left[\mathrm{m} \mathrm{s}^{-2}\right]_{(30}{ }^{\circ} \mathrm{C}\right)\end{array}$ & $\begin{array}{l}\text { Water concentration } \\
\left.[\mathrm{ppm}]_{(25}{ }^{\circ} \mathrm{C}\right)\end{array}$ \\
\hline$[\mathrm{bmim}]\left[\mathrm{Tf}_{2} \mathrm{~N}\right]$ & 48.8 & $1.20 \times 10^{-10}$ & 7000 \\
{$[\mathrm{omim}]\left[\mathrm{Tf}_{2} \mathrm{~N}\right]$} & 86.6 & $1.30 \times 10^{-10}$ & 2700 \\
{$\left[\mathrm{P}_{6,6,6,14}\right][\mathrm{DCA}]$} & 361.0 & $1.13 \times 10^{-10}$ & 12000 \\
{$\left[\mathrm{P}_{6,6,6,14}\right]\left[\mathrm{Tf}_{2} \mathrm{~N}\right]$} & 304.0 & $1.54 \times 10^{-11}$ & 1000
\end{tabular}


et-

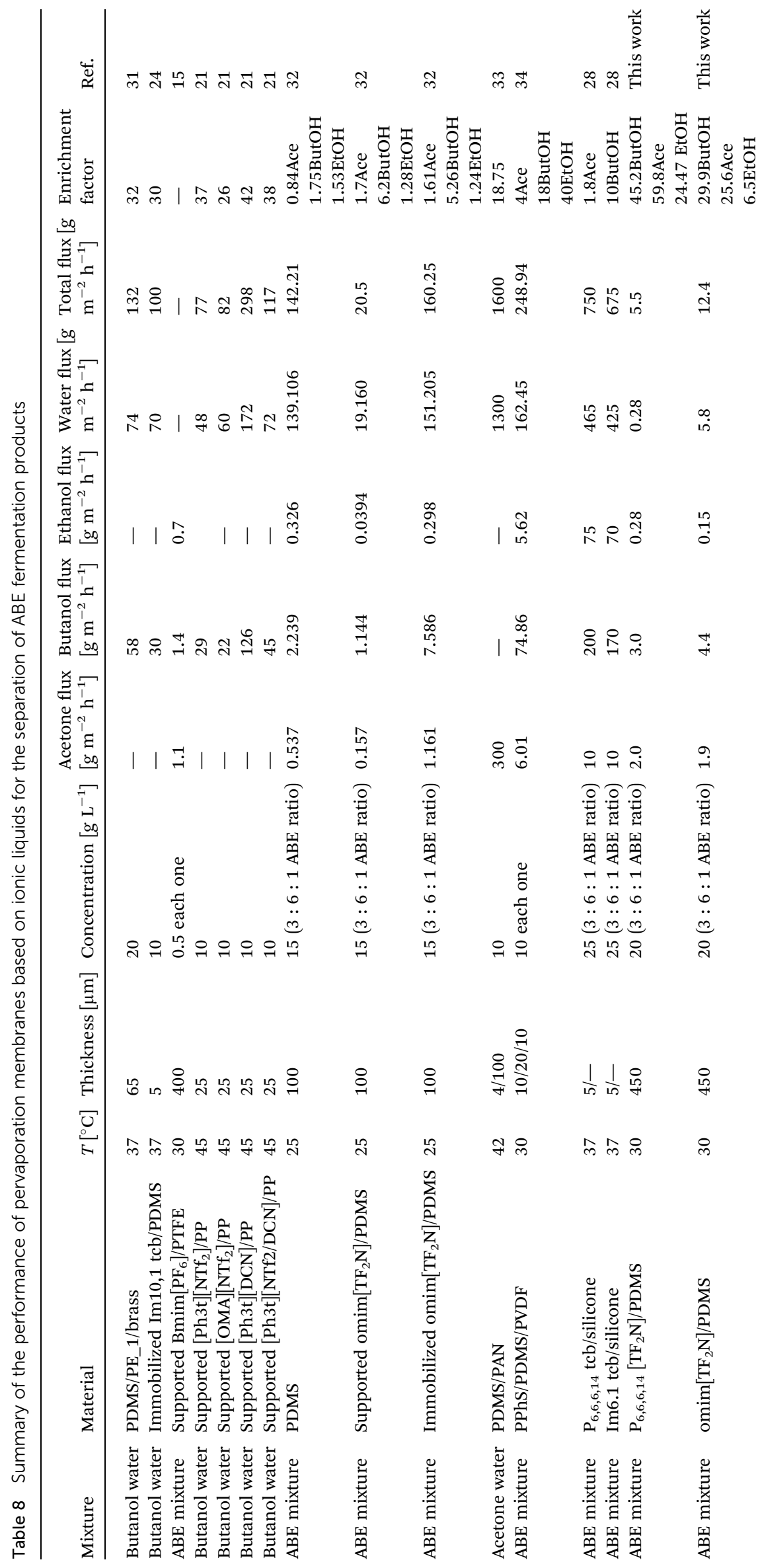


hanol and $50 \% \mathrm{w} / \mathrm{w}$ water when the pervaporation membrane was prepared with $[\mathrm{omim}]\left[\mathrm{Tf}_{2} \mathrm{~N}\right]$ and the enrichment ratios of butanol, acetone and ethanol were equal to 29.2, 25.3 and 6.2, respectively. Meanwhile, the pervaporation membrane prepared with $\left[\mathrm{P}_{6,6,6,14}\right]\left[\mathrm{Tf}_{2} \mathrm{~N}\right]$ allows the obtaining of a permeate with concentrations of $54.2 \%$ butanol, $36 \%$ acetone, $4.8 \%$ ethanol and only $5 \%$ water as well as enrichment ratios of butanol, acetone and ethanol equal to 45.2, 59.8 and 24.5, respectively. This last membrane can be considered the most competitive in terms of energy requirements because a subsequent distillation step would involve the processing of a low volume of a highly concentrated solution to obtain pure butanol.

Table 7 shows viscosity, diffusion coefficient of butanol and the concentration of water at saturation condition for each ionic liquid tested in this work. These values were obtained from the data sheets supplied by Iolitec, the equation proposed by Morgan and Fergunson and previously used by Merlet and coworkers, ${ }^{29}$ and by the Karl Fischer titration method for viscosity, diffusion coefficient and concentration of water at saturation, respectively. The values presented in this table show that both transport properties, viscosity and diffusion coefficient, do not have a significant influence on the values of transmembrane flux of butanol, which were reported in Table 4 . This fact can be explained by the larger resistance represented by the PDMS coating layers. Instead, the selectivity with respect to water (Table 5) seems to be strongly affected by the hydrophobicity of each ionic liquid. Thus, the thermodynamic equilibrium of the transferred species established at the interfaces inside the membrane structure could be the main parameter that controls the membrane performance.

\subsection{Comparison with data from the literature}

There is a significant body of literature on the separation of butanol from aqueous mixtures ${ }^{3,15,30}$ by means of pervaporation where the performance of different types of membranes has been reported. These studies are summarized in Table 8, which shows the characteristics (material and thickness) of each membrane as well as their operational conditions (temperature and initial concentrations) and performances reported as total transmembrane flux, flux per specie and the enrichment factor. Those results are compared with the PDMS-coated IL gel membranes that showed the best performance in this work.

It is possible to observe that the membrane prepared from a gel of $\left[\mathrm{P}_{6,6,6,14}\right]\left[\mathrm{Tf}_{2} \mathrm{~N}\right]$ shows the highest value of enrichment factor for butanol and acetone of this list. These values involve selectivities with respect to water equal to 892.0 and 1181.2 for butanol and acetone, respectively (Table 3). Nevertheless, higher selectivity involves lower permeability and the PDMScoated IL gel membranes show low total and specific transfer rates when compared with other membranes reported in the literature. In Table 7, there are two different group of membranes that have been reported, those with high permeability and selectivity and permeability ${ }^{\mathbf{1 4 1 8 , 2 9 , 3 1}}$ with thickness values ranging from 4 to $65 \mu \mathrm{m}$. Furthermore, other membranes ${ }^{22,30,34}$ show high permeability, but very low permeability for the recovery of butanol, and thicknesses ranged from 5 to $100 \mu \mathrm{m}$. In this framework, the membranes prepared in this work show the highest selectivity of solutes and their total transfer rate is up to 290 lower than the more permeable membrane reported in the literature; ${ }^{31}$ meanwhile the PDMS-coated IL gel membrane shows a thickness up to 113 times higher than membranes reported in the literature. ${ }^{\mathbf{1 8 , 2 2 , 3 1}}$ If this same comparison is carried out with the transfer of butanol, the most permeable membranes reported in the literature show values of transmembrane fluxes of butanol between 2.5 to 67 times higher than the membranes reported here, since most of the transfer decrease is related to the rejection of water. Thus, the PDMS-coated IL gel membranes developed in this work represent one of the most competitive pervaporation membranes for the recovery of butanol from ABE mixtures in terms of transport properties. Further research is necessary to reduce the whole thickness of the three-layer system as well as to test these membranes with real ABE fermentation broths.

Finally, it is worth noting that the membranes prepared and tested in this work were stable during the time spent on the whole set of experiments during a period of time close to two months. After this time, the membranes were taken out of the modules, their layers were separated and the PDMS layer was washed and analyzed by FT-IR spectroscopy, which showed that there was no modification detected in the PDMS layers after contact with the IL gel layers and after the pervaporation tests. This high stability can be explained by the protection that involves the PDMS coating.

\section{Conclusions}

This work reports the preparation of selective membranes based on a layer of ionic liquid gel coated by two PDMS layers. Membranes prepared with four different ionic liquids were tested in pervaporation tests to assess their performance in the separation of butanol from ABE solutions.

From the pervaporation tests, it seems to be verified that a synergic effect of the PDMS coating with the ionic liquid gel layer improves the selectivity because the flux of solutes is not significantly reduced when compared with the performance of a single PDMS layer; meanwhile, the transmembrane flux of water is significantly reduced compared with the same reference system. This fact can be mainly explained by the distribution of the species between each layer, which is given by the thermodynamic equilibrium established between the PDMS and the IL gel layers. The best membrane tested in this work, using $\left[\mathrm{P}_{6,6,6,14}\right]\left[\mathrm{Tf}_{2} \mathrm{~N}\right]$, showed solute/water selectivities equal to 892.0, 1181.2, and 483.0 for butanol, acetone, and ethanol, respectively. This membrane configuration could be promising to tune the selectivity of the membrane to different compounds depending on the IL gel layer used to prepare the coated membrane.

On the other hand, the permeate obtained with the $\left[\mathrm{P}_{6,6,6,14}\right]$ $\left[\mathrm{Tf}_{2} \mathrm{~N}\right]$-based membrane contains $54.2 \%$ butanol, $36 \%$ acetone, $4.8 \%$ ethanol and only $5 \%$ water. This last membrane can be considered the most competitive in terms of energy requirements because a subsequent distillation step would involve the 
processing of a low volume of a highly concentrated solution to obtain pure butanol.

The PDMS-coated $\left[\mathrm{P}_{6,6,6,14}\right]\left[\mathrm{Tf}_{2} \mathrm{~N}\right]$ gel membrane represents one of the most competitive pervaporation membranes for the recovery of butanol from $\mathrm{ABE}$ mixtures in terms of transport properties. Nevertheless, further research will be necessary in order to decrease the whole thickness of the three-layer system as well as to develop pervaporation experiments with real $\mathrm{ABE}$ fermentation broths.

\section{Conflicts of interest}

There are no conflicts to declare.

\section{Acknowledgements}

This research has been carried out with the financial support of the Project FONDECYT 1140208 (CONICYT Chile) and the Project RC-130006, CILIS, granted by Fondo de Innovación para la Competitividad, del Ministerio de Economía, Fomento y Turismo, Chile. The support obtained from the CONICYT Program of Doctoral Grants for the students René Cabezas (2013-No. 21130649) and Gastón Merlet (2013-No. 21130800) is gratefully acknowledged.

\section{References}

1 C. Xue, J. Zhao, L. Chen, S. T. Yang and F. Bai, Recent advances and state-of-the-art strategies in strain and process engineering for biobutanol production by Clostridium acetobutylicum, Biotechnol. Adv., 2017, 35, 310322.

2 C. Jin, M. Yao, H. Liu, C.-f. F. Lee and J. Ji, Progress in the production and application of n-butanol as a biofuel, Renewable Sustainable Energy Rev., 2011, 15, 4080-4106.

3 R. Cabezas, A. Plaza, G. Merlet and J. Romero, Effect of fluid dynamic conditions on the recovery of $\mathrm{ABE}$ fermentation products by membrane-based dense gas extraction, Chem. Eng. Process., 2015, 95, 80-89.

4 K. Kraemer, A. Harwardt, R. Bronneberg and W. Marquardt, Separation of butanol from acetone-butanol-ethanol fermentation by a hybrid extraction-distillation process, Comput. Chem. Eng., 2011, 35, 949-963.

5 P. H. Pfromm, V. Amanor-Boadu, R. Nelson, P. Vadlani and R. Madl, Bio-butanol vs. bio-ethanol: a technical and economic assessment for corn and switchgrass fermented by yeast or Clostridium acetobutylicum, Biomass Bioenergy, 2010, 34, 515-524.

6 P. T. Cardew and M. S. Le, in Membrane Processes - A Technology Guide, Royal Society of Chemistry, 1998.

7 J. Huang and M. M. Meagher, Pervaporative recovery of nbutanol from aqueous solutions and $\mathrm{ABE}$ fermentation broth using thin-film silicalite-filled silicone composite membranes, J. Membr. Sci., 2001, 192, 231-242.

8 N. Qureshi, M. M. Meagher, J. Huang and R. W. Hutkins, Acetone butanol ethanol (ABE) recovery by pervaporation using silicalite-silicone composite membrane from fed- batch reactor of Clostridium acetobutylicum, J. Membr. Sci., 2001, 187, 93-102.

9 F. Liu, L. Liu and X. Feng, Separation of acetone-butanolethanol (ABE) from dilute aqueous solutions by pervaporation, Sep. Purif. Technol., 2005, 42, 273-282.

10 Y. K. Ong, N. Widjojo and T.-S. Chung, Fundamentals of semi-crystalline poly(vinylidene fluoride) membrane formation and its prospects for biofuel (ethanol and acetone) separation via pervaporation, J. Membr. Sci., 2011, 378, 149-162.

11 D. Liu, G. Liu, L. Meng, Z. Dong, K. Huang and W. Jin, Hollow fiber modules with ceramic-supported PDMS composite membranes for pervaporation recovery of biobutanol, Sep. Purif. Technol., 2015, 146, 24-32.

12 R. Petrychkovych, K. Setnickova and P. Uchytil, The influence of water on butanol isomers pervaporation transport through polyethylene membrane, Sep. Purif. Technol., 2013, 107, 85-90.

13 S. Keskin, D. Kayrak-Talay, U. Akman and Ö. Hortaçsu, A review of ionic liquids towards supercritical fluid applications, J. Supercrit. Fluids, 2007, 43, 150-180.

14 R. Fortunato, C. A. M. Afonso, M. A. M. Reis and J. G. Crespo, Supported liquid membranes using ionic liquids: study of stability and transport mechanisms, J. Membr. Sci., 2004, 242, 197-209.

15 A. Plaza, G. Merlet, A. Hasanoglu, M. Isaacs, J. Sanchez and J. Romero, Separation of butanol from ABE mixtures by sweep gas pervaporation using a supported gelled ionic liquid membrane: Analysis of transport phenomena and selectivity, J. Membr. Sci., 2013, 444, 201-212.

16 J. Wang, A. Zhu and L. Li, Sustainable Catalysis Systems Based on Ionic Liquids, in Sustainable Catalytic Processes, ed. B. Saha, M. Fan and J. Wang, Elsevier, Amsterdam, 2015, ch. 3, pp. 61-98.

17 B. Sasikumar, G. Arthanareeswaran and A. F. Ismail, Recent progress in ionic liquid membranes for gas separation, $J$. Mol. Liq., 2018, 266, 330-341.

18 J. Wang, J. Luo, S. Feng, H. Li, Y. Wan and X. Zhang, Recent development of ionic liquid membranes, Green Energy \& Environment, 2016, 1, 43-61.

19 X. Zhang, Z. Tu, H. Li, K. Huang, X. Hu, Y. Wu and D. R. MacFarlane, Selective separation of $\mathrm{H}_{2} \mathrm{~S}$ and $\mathrm{CO}_{2}$ from $\mathrm{CH}_{4}$ by supported ionic liquid membranes, J. Membr. Sci., 2017, 543, 282-287.

20 A. P. de los Ríos, F. J. Hernández-Fernández, M. Rubio, D. Gómez and G. Víllora, Highly selective transport of transesterification reaction compounds through supported liquid membranes containing ionic liquids based on the tetrafluoroborate anion, Desalination, 2010, 250, 101-104.

$21 \mathrm{H}$. R. Cascon and S. K. Choudhari, 1-Butanol pervaporation performance and intrinsic stability of phosphonium and ammonium ionic liquid-based supported liquid membranes, J. Membr. Sci., 2013, 429, 214-224.

22 B. A. Voss, J. E. Bara, D. L. Gin and R. D. Noble, Physically Gelled Ionic Liquids: Solid Membrane Materials with Liquidlike $\mathrm{CO}_{2}$ Gas Transport, Chem. Mater., 2009, 21, 3027-3029. 
23 M. Kohoutová, A. Sikora, Š. Hovorka, A. Randová, J. Schauer, M. Tišma, K. Setničková, R. Petričkovič, S. Guernik, N. Greenspoon and P. Izák, Influence of ionic liquid content on properties of dense polymer membranes, Eur. Polym. J., 2009, 45, 813-819.

24 S. Heitmann, J. Krings, P. Kreis, A. Lennert, W. R. Pitner, A. Górak and M. M. Schulte, Recovery of n-butanol using ionic liquid-based pervaporation membranes, Sep. Purif. Technol., 2012, 97, 108-114.

25 P. Izák, W. Ruth, Z. Fei, P. J. Dyson and U. Kragl, Selective removal of acetone and butan-1-ol from water with supported ionic liquid-polydimethylsiloxane membrane by pervaporation, Chem. Eng. J., 2008, 139, 318-321.

26 M. A. Malik, M. A. Hashim and F. Nabi, Ionic liquids in supported liquid membrane technology, Chem. Eng. J., 2011, 171, 242-254.

27 Y. Luo, S. Tan, H. Wang, F. Wu, X. Liu, L. Li and Z. Zhang, PPMS composite membranes for the concentration of organics from aqueous solutions by pervaporation, Chem. Eng. J., 2008, 137, 496-502.

28 P. Rdzanek, S. Heitmann, A. Górak and W. Kamiński, Application of supported ionic liquid membranes (SILMs) for biobutanol pervaporation, Separation and Purification Technology, 2015.
29 G. Merlet, F. Uribe, C. Aravena, M. Rodríguez, R. Cabezas, E. Quijada-Maldonado and J. Romero, Separation of fermentation products from ABE mixtures by perstraction using hydrophobic ionic liquids as extractants, J. Membr. Sci., 2017, 537, 337-343.

30 P. Rdzanek, J. Marszałek and W. Kamiński, Biobutanol concentration by pervaporation using supported ionic liquid membranes, Sep. Purif. Technol., 2018, 196, 124-131.

31 S.-Y. Li, R. Srivastava and R. S. Parnas, Separation of 1butanol by pervaporation using a novel tri-layer PDMS composite membrane, J. Membr. Sci., 2010, 363, 287-294.

32 N. L. Mai, S. H. Kim, S. H. Ha, H. S. Shin and Y.-M. Koo, Selective recovery of acetone-butanol-ethanol from aqueous mixture by pervaporation using immobilized ionic liquid polydimethylsiloxane membrane, Korean J. Chem. Eng., 2013, 30, 1804-1809.

33 J. Niemistö, W. Kujawski and R. L. Keiski, Pervaporation performance of composite poly(dimethyl siloxane) membrane for butanol recovery from model solutions, $J$. Membr. Sci., 2013, 434, 55-64.

34 K. Y. Jee and Y. T. Lee, Preparation and characterization of siloxane composite membranes for n-butanol concentration from ABE solution by pervaporation, $J$. Membr. Sci., 2014, 456, 1-10. 